\title{
Risk Factors and Clinical Outcomes of Non-Curative Resection in Patients with Early Gastric Cancer Treated with Endoscopic Submucosal Dissection: A Retrospective Multicenter Study in Korea
}

\author{
Si Hyung Lee ${ }^{1}$, Min Cheol Kim', Seong Woo Jeon², Kang Nyeong Lee ${ }^{3}$, Jong Jae Park ${ }^{4}$, Su Jin Hong ${ }^{5}$ and Korean Society of \\ Gastrointestinal Endoscopy Endoscopic Submucosal Dissection Research Group
}

Department of Internal Medicine, ${ }^{1}$ Yeungnam University College of Medicine, Daegu, ${ }^{2}$ School of Medicine, Kyungpook National University, Daegu, ${ }^{3}$ Hanyang University College of Medicine, Seoul, ${ }^{4}$ Korea University College of Medicine, Seoul, ${ }^{5}$ Soonchunhyang University College of Medicine, Bucheon, Korea

Background/Aims: The purpose of this study was to investigate the risk factors and long-term clinical outcomes of non-curative resection (NCR) in a large-scale patient population.

Methods: We retrospectively analyzed the clinical data of 3,094 patients who underwent endoscopic submucosal dissection (ESD) of early gastric cancer from March 2005 to March 2018 at 13 institutions in Korea. We analyzed the risk factors for NCR and the survival between patients with curative resection and those with NCR with no additional treatment.

Results: The NCR rate was $21.4 \%$ (661/3,094). In multivariate regression analysis, the risk factors affecting NCR with ESD were old age, undifferentiated tumor, tumor location in the upper body, tumor size $\geq 2 \mathrm{~cm}$, and presence of an ulcer. In Cox proportional hazard regression analysis, tumor size $\geq 2 \mathrm{~cm}$, submucosal invasion, positive horizontal margin, and lymphovascular invasion were risk factors for local recurrence. In Kaplan-Meier analysis, there was no statistically significant difference in the overall survival between the two groups (log-rank $p=0.788)$. However, disease-specific survival was significantly lower in the NCR group $(\log$-rank $p=0.038)$.

Conclusions: Clinicians should be aware of the risk factors for NCR and local recurrence after ESD for early gastric cancer, and should consider providing additional treatment after NCR. Clin Endosc 2020;53:196-205

Key Words: Early gastric cancer; Endoscopic submucosal dissection; Follow-up; Incomplete resection

\section{INTRODUCTION}

Gastric cancer is the fourth most common cancer and has the second highest cancer-related mortality rate worldwide. ${ }^{1,2}$ Early detection and early treatment can significantly reduce mortality., ${ }^{3,4}$ Korea, with the increase in individual health examinations and the expansion of the national cancer

Received: June 22, 2019 Revised: August 12, 2019

Accepted: August 13, 2019

Correspondence: Seong Woo Jeon

Department of Internal Medicine, School of Medicine, Kyungpook National University Chilgok Hospital, 807 Hoguk-ro, Buk-gu, Daegu 41404, Korea Tel: +82-53-200-3517, Fax: +82-53-200-2027, E-mail: swjeon@knu.ac.kr ORCID: https://orcid.org/0000-0002-9539-9389

cc This is an Open Access article distributed under the terms of the Creative Commons Attribution Non-Commercial License (http://creativecommons.org/ licenses/by-nc/3.0) which permits unrestricted non-commercial use, distribution, and reproduction in any medium, provided the original work is properly cited. screening program that provides upper gastrointestinal endoscopy every 2 years for people aged $>40$ years, the number of patients diagnosed with early gastric cancer (EGC) has increased. ${ }^{2,5}$ Traditionally, surgical resection was the standard treatment for gastric cancer; however, in recent years, endoscopic resection has become widely used. At present, endoscopic submucosal dissection (ESD) is accepted as a standard treatment for gastric cancer in patients with a negligible risk of lymph node or distant metastasis. ${ }^{6.9}$

Endoscopic resection of EGC is indicated on the basis of tumor differentiation, size, ulceration, and invasion depth, and its goal is "curative resection" (CR). ${ }^{10}$ In cases of non-curative resection (NCR), additional treatment is needed because of local recurrence and lymph node metastasis, for which the standard treatment is gastrectomy with lymphadenectomy. ${ }^{11-13}$ However, for reasons such as an increased proportion of 
elderly patients owing to the increase in average life expectancy, concomitant diseases, poor general health, or a patient's refusal to undergo surgery, patients with NCR may be treated with redo-ESD, argon plasma coagulation, or careful observation without further treatment. ${ }^{14-16}$

Although several studies have reported the long-term clinical outcomes of NCR in patients with EGC treated with ESD, studies on large-scale populations are lacking. ${ }^{17-19}$ The aims of this retrospective multicenter study were to investigate the risk factors associated with NCR and to assess the long-term clinical outcomes after NCR with no additional treatment in a large-scale patient population.

\section{MATERIALS AND METHODS}

\section{Study design}

We performed a retrospective multicenter study at 13 Korean institutions by using ESD registry data collected under the supervision of the ESD research group of the Korean Society of Gastrointestinal Endoscopy. The study protocol adhered to the ethical principles of the Declaration of Helsinki and was approved by the institutional review board of each institution (2019-05-035).

\section{Patients}

We retrospectively analyzed the clinical data of 3,929 patients aged $>20$ years who underwent endoscopic resection of EGC from March 2005 to March 2018 at 13 institutions in Korea. We excluded patients who met any of the following exclusion criteria: (1) history of previous endoscopic resection $(n=101),(2)$ history of previous abdominal surgery for stomach cancer ( $n=14)$, (3) EGC treated with endoscopic mucosal resection ( $n=237)$, (4) surgery performed immediately after ESD because of NCR or meeting the expanded criteria $(n=115)$, or (5) loss to follow-up or $<6$ months of follow-up ( $n=368$ ). A total of 3,094 patients were finally enrolled (Fig. 1).

\section{Endoscopic submucosal dissection procedure}

Among patients diagnosed with EGC by using standard endoscopy, ESD was performed in those who met the indications for endoscopic resection. All patients were sedated using midazolam and/or propofol with cardiopulmonary monitoring. The target lesion was identified and marking dots were placed circumferentially $2 \mathrm{~mm}$ outside the lesion to determine the ESD range. Thereafter, a submucosal solution, such as saline or sodium hyaluronate with epinephrine, was injected into the submucosal layer to lift it off the muscle layer and a circumferential mucosal incision was made outside the marking dots with an electrosurgical knife. The submucosal layer was then dissected with an IT-knife or an IT-knife2 while performing hemostasis on any oozing vessel or on vessels exposed both during and after the procedure.

\section{Histopathological evaluation and curability}

The endoscopically resected specimens were sectioned at 2-mm intervals and stained with hematoxylin and eosin after fixation in $10 \%$ formalin and embedding in paraffin for histopathological evaluation. At each institution, a pathologist evaluated the specimens for histopathological type, invasion depth, horizontal and vertical margins, ulcerations, and lymphovascular invasion according to the Japanese classification of gastric carcinoma. ${ }^{20}$ Differentiated adenocarcinoma included tubular adenocarcinoma and papillary adenocarcinoma, whereas undifferentiated adenocarcinoma included poorly differentiated adenocarcinoma, signet ring cell carcinoma, and mucinous adenocarcinoma. Tumoral infiltration of the submucosa (SM) was subclassified as SM1 $(<500 \mu \mathrm{m}$ from the muscularis mucosa) or SM2 ( $\geq 500 \mu \mathrm{m}$ from the muscularis mucosa).

\footnotetext{
Patients aged over 20 years who underwent endoscopic resection of EGCA $(n=3,929)$

\begin{tabular}{|l|ll|}
\hline & Excluded & \\
& Previous Hx. of endoscopic resection & $(n=101)$ \\
Previous Hx. of abdominal surgery for stomach cancer & $(n=14)$ \\
& Treated by EMR & $(n=237)$ \\
Immediately surgery after ESD for NCR or expanded criteria & $(n=115)$ \\
& Lost to follow-up and less than 6 months of follow-up & $(n=368)$ \\
\hline
\end{tabular}

Finally enrolled in this study $(n=3,094)$

Fig. 1. Flowchart of patient enrollment. EGCA, early gastric cancer; EMR, endoscopic mucosal resection; ESD, endoscopic submucosal dissection; $\mathrm{Hx}$, history; NCR, non-curative resection.
} 
Table 1. Baseline Characteristics

\begin{tabular}{|c|c|c|c|}
\hline & $\begin{array}{l}\text { Curative resection } \\
\qquad(n=2,433)\end{array}$ & $\begin{array}{l}\text { Non-curative resection } \\
\qquad(n=661)\end{array}$ & $p$-value \\
\hline Age, yr & $63.51 \pm 9.57$ & $63.89 \pm 10.41$ & 0.404 \\
\hline$\geq 65 \mathrm{yr}$ & $1,253(51.5 \%)$ & $317(48.0 \%)$ & 0.106 \\
\hline Male & $1,777(73.0 \%)$ & $443(67.0 \%)$ & 0.002 \\
\hline Family history of stomach cancer & $156(6.4 \%)$ & $33(5.0 \%)$ & 0.177 \\
\hline Smoking history & & & 0.629 \\
\hline Non-smoker & $1408(57.9 \%)$ & $396(59.9 \%)$ & \\
\hline Ex-smoker & $546(22.4 \%)$ & $143(21.5 \%)$ & \\
\hline Current smoker & $479(19.7 \%)$ & $122(18.5 \%)$ & \\
\hline \multicolumn{4}{|l|}{ Co-morbidity disease } \\
\hline Hypertension & $945(38.8 \%)$ & $247(37.4 \%)$ & 0.490 \\
\hline Diabetes mellitus & $418(17.2 \%)$ & $116(17.5 \%)$ & 0.824 \\
\hline Cardiovascular disease & $145(6.0 \%)$ & $36(5.4 \%)$ & 0.618 \\
\hline Cerebrovascular attack & $112(4.6 \%)$ & $31(4.7 \%)$ & 0.925 \\
\hline Liver cirrhosis & $36(1.5 \%)$ & $15(2.3 \%)$ & 0.157 \\
\hline Chronic kidney disease & $17(0.7 \%)$ & $9(1.4 \%)$ & 0.098 \\
\hline Aspirin use & $259(10.6 \%)$ & $78(11.8 \%)$ & 0.398 \\
\hline Pre-procedure diagnosis & & & $<0.001$ \\
\hline Adenoma or atypical cells & $1,043(42.9 \%)$ & $135(20.4 \%)$ & \\
\hline Differentiated & $1,302(53.5 \%)$ & $367(55.5 \%)$ & \\
\hline Undifferentiated & $88(3.6 \%)$ & $159(24.1 \%)$ & \\
\hline \multicolumn{4}{|l|}{ Post-procedure diagnosis } \\
\hline Differentiated & $2,325(95.6 \%)$ & $438(66.3 \%)$ & $<0.001$ \\
\hline Undifferentiated & $108(4.4 \%)$ & $223(33.7 \%)$ & \\
\hline Tumor location, long axis & & & $<0.001$ \\
\hline Lower & $1,636(67.2 \%)$ & $325(49.2 \%)$ & \\
\hline Middle & $640(26.3 \%)$ & $261(39.5 \%)$ & \\
\hline Upper & $157(6.5 \%)$ & $75(11.3 \%)$ & \\
\hline Tumor location, short axis & & & 0.295 \\
\hline Lesser curvature & $973(40.0 \%)$ & $254(38.4 \%)$ & \\
\hline Greater curvature & $510(21.0 \%)$ & $139(21.0 \%)$ & \\
\hline Posterior wall & $496(20.4 \%)$ & $156(23.6 \%)$ & \\
\hline Anterior wall & $454(18.7 \%)$ & $112(16.9 \%)$ & \\
\hline Gross type & & & 0.001 \\
\hline Elevated & $1,134(46.6 \%)$ & $272(41.1 \%)$ & \\
\hline Flat & $478(19.6 \%)$ & $172(26.0 \%)$ & \\
\hline Depressed & $821(33.7 \%)$ & $217(32.8 \%)$ & \\
\hline Tumor size, mm & $14.56 \pm 9.89$ & $23.13 \pm 14.12$ & $<0.001$ \\
\hline Ulceration & $272(11.2 \%)$ & $119(18.0 \%)$ & $<0.001$ \\
\hline Depth of tumor & & & $<0.001$ \\
\hline Mucosal lesion & $2,336(96.0 \%)$ & $394(59.6 \%)$ & \\
\hline Submucosal lesion & $97(4.0 \%)$ & $262(40.4 \%)$ & \\
\hline
\end{tabular}


Table 1. Continued

\begin{tabular}{|c|c|c|c|}
\hline & $\begin{array}{l}\text { Curative resection } \\
\qquad(n=2,433)\end{array}$ & $\begin{array}{l}\text { Non-curative resection } \\
\qquad(n=661)\end{array}$ & $p$-value \\
\hline Procedure time, $\min$ & $42.88 \pm 33.77$ & $62.46 \pm 45.42$ & $<0.001$ \\
\hline En bloc resection & $2,433(100.0 \%)$ & $552(83.5 \%)$ & $<0.001$ \\
\hline \multicolumn{4}{|l|}{ Complication } \\
\hline Bleeding, during procedure & $405(16.6 \%)$ & $140(21.2 \%)$ & 0.007 \\
\hline Bleeding, after procedure & $157(6.5 \%)$ & $51(7.7 \%)$ & 0.250 \\
\hline Hypoxia & $0(0.0 \%)$ & $2(0.1 \%)$ & 0.046 \\
\hline Perforation & $28(1.2 \%)$ & $18(2.7 \%)$ & 0.003 \\
\hline Helicobacter infection state & & & $<0.001$ \\
\hline Non-infected & $814(33.5 \%)$ & $234(35.4 \%)$ & \\
\hline Infected, successfully eradication & $808(33.2 \%)$ & $169(25.6 \%)$ & \\
\hline Infected, eradication, but failed & $67(2.8 \%)$ & $7(1.1 \%)$ & \\
\hline Infected, no treatment & $358(14.7 \%)$ & $116(17.5 \%)$ & \\
\hline Un-evaluated & $386(15.9 \%)$ & $135(20.4 \%)$ & \\
\hline Follow up period, mo & $50.1 \pm 29.6$ & $50.6 \pm 28.5$ & 0.308 \\
\hline Local recurrence & $61(2.5 \%)$ & $70(10.6 \%)$ & $<0.001$ \\
\hline Recurrence at other site & $141(5.8 \%)$ & $35(5.3 \%)$ & 0.622 \\
\hline Synchronous EGC $(<1 \mathrm{yr})$ & $68(2.8 \%)$ & $13(2.0 \%)$ & 0.237 \\
\hline Metachronous EGC ( $\geq 1 \mathrm{yr})$ & $73(3.0 \%)$ & $22(3.3 \%)$ & 0.665 \\
\hline
\end{tabular}

EGC, early gastric cancer.

Table 2. Characteristics of Non-Curative Resection

\begin{tabular}{lc}
\hline & $\begin{array}{c}\text { Non-curative } \\
\text { resection }(\boldsymbol{n}=\mathbf{6 6 1})\end{array}$ \\
\hline Resection & $552(83.5 \%)$ \\
En bloc resection & $109(16.5 \%)$ \\
Piecemeal resection & $335(50.7 \%)$ \\
Tumor size $\geq 2 \mathrm{~cm}$ & \\
Depth of tumor & $394(59.6 \%)$ \\
M & $74(11.2 \%)$ \\
SM1 & $193(29.2 \%)$ \\
$\geq$ SM2 & \\
Margin involvement & $437(66.1 \%)$ \\
Clear margin & $142(21.5 \%)$ \\
Horizontal margin positive only & $67(10.1 \%)$ \\
Vertical margin positive only & $15(2.3 \%)$ \\
Both margin positive & $51(7.7 \%)$ \\
Vertical margin positive + SM invasion & $87(13.2 \%)$ \\
Lymphovascular invasion & $259(39.2 \%)$ \\
\hline Procedure time $\geq 60$ min &
\end{tabular}

M, mucosa; SM, submucosa.
According to the Japanese gastric cancer treatment guidelines, the indications for CR are as follows: en bloc resection, tumor size $\leq 2 \mathrm{~cm}$, histologically differentiated type, pTla, negative horizontal margin (HM0), negative vertical margin (VM0), and no lymphovascular invasion. In addition, a resection was considered curative for the expanded indications when all of the following conditions were fulfilled: en bloc resection, HM0, VM0, no lymphovascular invasion with (1) tumor size $>2 \mathrm{~cm}$, differentiated, pTla, no ulcerative findings; (2) tumor size $\leq 3 \mathrm{~cm}$, differentiated, pTla, ulcerative findings; (3) tumor size $\leq 2 \mathrm{~cm}$, undifferentiated, pTla, no ulcerative findings; and (4) tumor size $\leq 3 \mathrm{~cm}$, differentiated, pT1b (SM1). Any resection that did not satisfy any of the above criteria (expanded indications) was considered NCR.

\section{Follow-up and clinical outcomes}

After ESD, regular follow-up was performed at 3 months, 6 months, and every year thereafter. In this study, local recurrence was defined as a recurrence of the index cancer at the site of ESD. Synchronous cancer was defined as a development of new cancer at a site other than the ESD site within 1 year after ESD. Metachronous cancer was defined as the development of new cancer beyond 1 year after ESD. Overall survival (OS) was defined as the period from the initial ESD until 
death due to any cause or last patient contact. Disease-specific survival (DSS) was defined as the period from the initial ESD until gastric cancer-related death or last patient contact. Disease-free survival was defined as the period from the initial ESD to local or distant recurrence of the index cancer, or death or last patient contact.

\section{Statistical analysis}

Continuous and categorical variables were expressed as mean \pm standard deviation and $n(\%)$, respectively. Patient characteristics were analyzed for the status of NCR by using Student's $t$-test for continuous variables and the chi-square test or Fisher's exact test, as appropriate, for categorical variables. Logistic regression analysis was used to determine the risk factors for NCR. The odds ratio (OR) was considered to be statistically significant if the $95 \%$ confidence interval (CI) did not include 1.0. Cumulative local recurrence rate, OS, and DSS were calculated according to the Kaplan-Meier method and analyzed using the log-rank test. Cox proportional hazard regression analysis was used to calculate univariate and multivariate-adjusted hazard ratios and 95\% CIs for risk factors for local recurrence in the follow-up. Statistical analysis was performed using SPSS version 25.0 (IBM, Armonk, NY, USA), and the level of statistical significance was set at $p<0.05$.

\section{RESULTS}

\section{Baseline characteristics}

Of the 3,094 patients with EGC treated with ESD, 661 patients $(21.4 \%)$ were found to have undergone NCR. The baseline characteristics of the NCR group are shown in Table 1. No differences in age, family history, smoking history, or comorbidities were seen between the two groups; however, the proportion of male patients in the CR group was higher than that in the NCR group. Certain characteristics of EGC,

Table 3. Risk Factors for Non-Curative Resection

\begin{tabular}{|c|c|c|c|c|}
\hline \multirow{2}{*}{ Variables } & \multicolumn{2}{|c|}{ Univariate analysis } & \multicolumn{2}{|c|}{ Multivariate analysis } \\
\hline & OR (95\% CI) & $p$-value & OR $(95 \% \mathrm{CI})$ & $p$-value \\
\hline \multicolumn{5}{|l|}{ Age } \\
\hline$<65 \mathrm{yr}$ & 1 & $<0.001$ & 1 & $<0.001$ \\
\hline$\geq 65 \mathrm{yr}$ & $1.44(1.18-1.76)$ & & $1.42(1.17-1.74)$ & \\
\hline \multicolumn{5}{|l|}{ Sex } \\
\hline Male & 1 & 0.983 & & \\
\hline Female & $1.00(0.81-1.25)$ & & & \\
\hline \multicolumn{5}{|c|}{ Tumor histopathology } \\
\hline Differentiated & 1 & $<0.001$ & 1 & $<0.001$ \\
\hline Undifferentiated & $9.18(6.96-12.11)$ & & $9.47(7.23-12.41)$ & \\
\hline \multicolumn{5}{|l|}{ Tumor location } \\
\hline Lower & 1 & & 1 & \\
\hline Middle & $1.58(1.28-1.95)$ & $<0.001$ & $1.57(1.27-1.94)$ & $<0.001$ \\
\hline Upper & $2.14(1.53-3.01)$ & $<0.001$ & $2.17(1.55-3.05)$ & $<0.001$ \\
\hline \multicolumn{5}{|l|}{ Gross type } \\
\hline Elevated & 1 & & & \\
\hline Flat & $1.19(0.92-1.54)$ & 0.187 & & \\
\hline Depressed & $1.14(0.90-1.44)$ & 0.277 & & \\
\hline \multicolumn{5}{|l|}{ Tumor size } \\
\hline$<2 \mathrm{~cm}$ & 1 & $<0.001$ & 1 & $<0.001$ \\
\hline$\geq 2 \mathrm{~cm}$ & $3.88(3.17-4.76)$ & & $3.81(3.12-4.66)$ & \\
\hline \multicolumn{5}{|l|}{ Ulceration } \\
\hline No & 1 & $<0.001$ & 1 & $<0.001$ \\
\hline Yes & $1.89(1.43-2.48)$ & & $1.93(1.47-2.53)$ & \\
\hline
\end{tabular}

$\mathrm{CI}$, confidence interval; OR, odds ratio. 
including undifferentiated carcinoma, upper third location, large tumor, ulceration, and submucosal invasion, were more frequent in the NCR group. With respect to the procedure, the mean procedure time was longer and complications related to the procedure were more frequent in the NCR group. Table 2 shows the characteristics of the NCR group.

\section{Independent risk factors for non-curative resection}

Table 3 shows the risk factors for NCR after ESD in patients with EGC. In multivariate regression analysis after adjusting for confounding factors, the risk factors affecting NCR of ESD were old age (OR, 1.42; 95\% CI, 1.17-1.74; $p<0.001$ ), undifferentiated tumor (OR, 9.47; 95\% CI, 7.23-12.41; $p<0.001$ ), tumor location in the upper body (OR, 2.17; 95\% CI, 1.55-3.05; $p<0.001$ ), tumor size $\geq 2 \mathrm{~cm}$ (OR, 3.81; 95\% CI, 3.12-4.66; $p<0.001$ ), and presence of an ulcer (OR, 1.93; 95\% CI, 1.47-2.53; $p<0.001)$.

\section{Local recurrence after non-curative resection}

During the study, the local recurrence rate was significantly higher in the NCR group than in the CR group (10.6\% vs. $2.5 \%$, $p<0.001)$ (Table 1). The cumulative local recurrence rate, calculated using Kaplan-Meier analysis, was significantly higher in the NCR group than in the CR group (Fig. 2). However, the cumulative recurrence rate at distant sites was not related to NCR (Fig. 3). Table 4 shows the risk factors affecting local recurrence. In Cox proportional hazard regression analysis, after adjusting for confounding factors, a tumor size of $\geq 2 \mathrm{~cm}$ (OR, 1.51; 95\% CI, 1.05-2.17; $p<0.028$ ), submucosal invasion (SM1: OR, 1.84 ; 95\% CI, $1.13-3.51 ; p=0.017$ and $\geq S M 2$ : OR, $1.84 ; 95 \%$ $\mathrm{CI}, 1.05-3.21 ; p=0.033)$, positive horizontal margin (OR, 3.78; 95\% CI, 2.38-6.00; $p<0.001$ ), and lymphovascular invasion (OR, 2.58; 95\% CI, 1.33-5.01; $p=0.005$ ) were risk factors for local recurrence.

\section{Overall survival rate and disease-specific survival rate after non-curative resection}

A comparison by Kaplan-Meier analysis of the OS of the CR and NCR groups when patients received no additional surgery is shown in Fig. 4. The OS rates at 3, 5, and 10 years
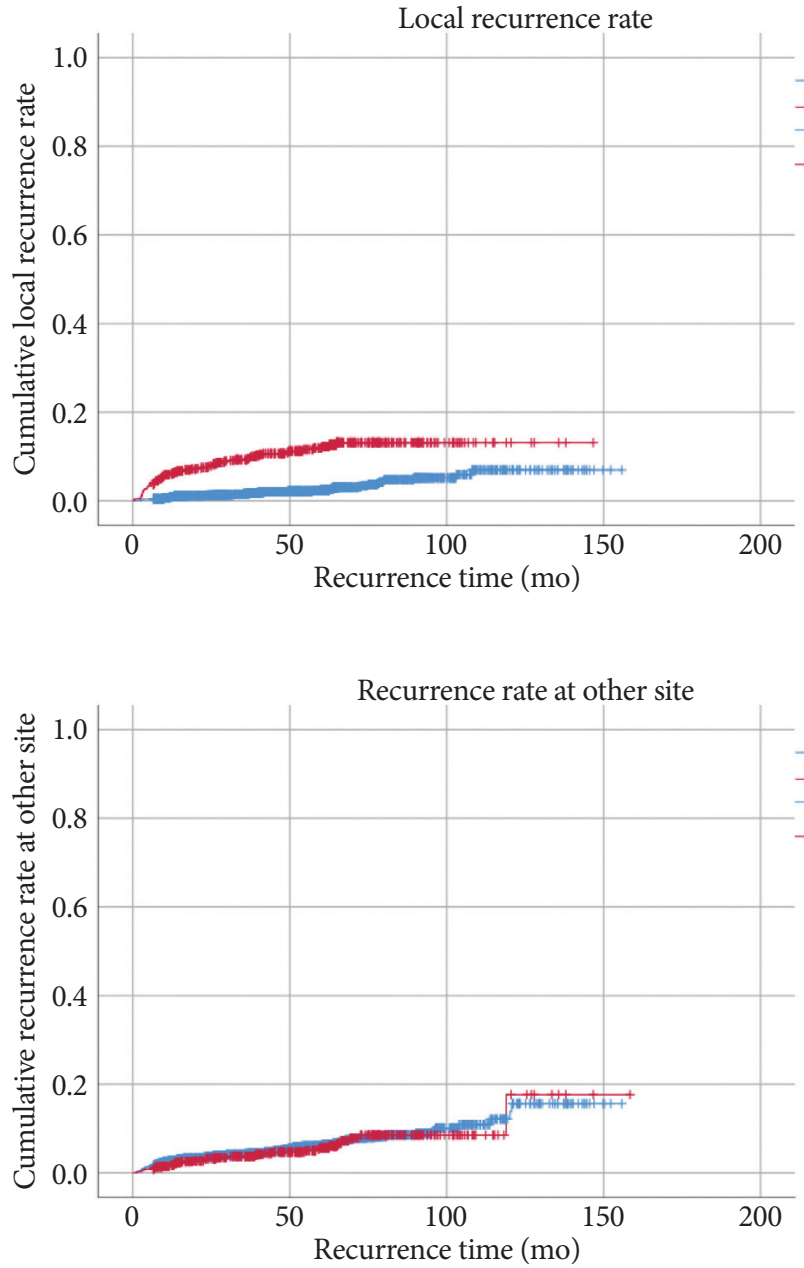

Endoscopic resection $\rightarrow$ Curative resection

$\neg$ Non-curative resection

+ Curative resection-censored

+ Non-curative resectioncensored
Fig. 2. Kaplan-Meier analysis for cumulative recurrence rates at previous endoscopic submucosal dissection site according to non-curative resection. Log-rank $p<0.001$.
Endoscopic resection

$\neg$ Curative resection

$\neg$ Non-curative resection

- Curative resection-censored

+ Non-curative resectioncensored

Fig. 3. Kaplan-Meier analysis for cumulative recurrence rates at other site according to non-curative resection. Log-rank $p=0.585$. 
were $99.4 \%$, 98.8\%, and $97.1 \%$, respectively, in the CR group and $99.4 \%, 98.9 \%$, and $96.8 \%$, respectively, in the NCR group. There was no statistically significant difference in OS between the two groups (log-rank $p=0.788$ ). Fig. 5 . shows the Kaplan-Meier analysis of DSS between the two groups. The
DSS rates at 3, 5, and 10 years were $100 \%, 99.9 \%$, and $99.7 \%$, respectively, in the CR group and $99.6 \%, 99.3 \%$, and $99.3 \%$, respectively, in the NCR group. DSS was significantly lower in the NCR group than in the CR group ( $\log$-rank $p=0.038$ ).

Table 4. Risk Factors Affecting Local Recurrence at Previous Endoscopic Submucosal Dissection Site after Endoscopic Submucosal Dissection

\begin{tabular}{|c|c|c|c|c|}
\hline \multirow{2}{*}{ Variables } & \multicolumn{2}{|c|}{ Univariate analysis } & \multicolumn{2}{|c|}{ Multivariate analysis } \\
\hline & HR (95\% CI) & $p$-value & HR (95\% CI) & $p$-value \\
\hline \multicolumn{5}{|l|}{ Age } \\
\hline$<65 \mathrm{yr}$ & 1 & 0.342 & & \\
\hline$\geq 65 \mathrm{yr}$ & $1.19(0.84-1.68)$ & & & \\
\hline \multicolumn{5}{|l|}{ Sex } \\
\hline Male & 1 & 0.067 & 1 & 0.105 \\
\hline Female & $0.67(0.44-1.03)$ & & $0.71(0.47-1.08)$ & \\
\hline
\end{tabular}

Post-procedure diagnosis

$\begin{array}{lcc}\text { Differentiated } & 1 & 0.136 \\ \text { Undifferentiated } & 1.45(0.89-2.37) & \end{array}$

Tumor location

Lower

Middle

Upper

1

$1.15(0.78-1.69)$

$1.25(0.69-2.26)$

Tumor size

$<2 \mathrm{~cm}$

1

$\geq 2 \mathrm{~cm}$

$1.41(0.97-2.04)$

\section{Depth of tumor}

M

SM1

ZSM2

1

$1.82(1.01-3.27)$

$1.59(0.86-2.93)$

1

$3.50(2.17-5.64)$

Yes

1

$1.22(0.57-2.60)$

Yes

Lymphovascular invasion

No

1

Yes

$2.65(1.35-5.21)$

1

$\mathrm{No}^{\text {a) }}$

$\mathrm{Yes}^{\mathrm{b})}$

$1.25(0.80-1.93)$

$1.17(0.74-1.84)$

Un-evaluated
0.482

0.465

0.071

1

0.028

$1.51(1.05-2.17)$

1

0.046

$1.99(1.13-3.51)$

0.017

0.137

$1.84(1.05-3.21)$

0.033

$<0.001$

1

$<0.001$

$3.78(2.38-6.00)$

0.608

0.005

1

0.005

M, mucosa; SM, submucosa

a) , confidence interval; $\mathrm{HR}$, hazard ratio; $\mathrm{M}$, mucosa,
${ }^{\mathrm{b}}$,infected and infected but successfully eradicated.

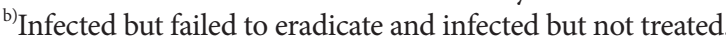




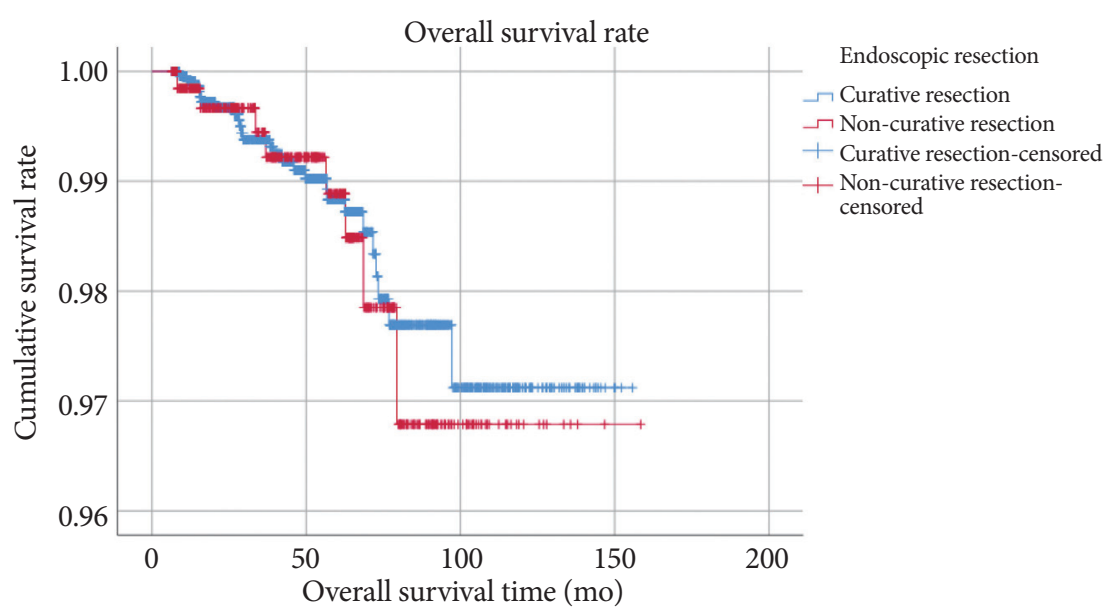

\begin{tabular}{lccc}
\hline Overall survival time & $3 \mathrm{yr}$ & $5 \mathrm{yr}$ & $10 \mathrm{yr}$ \\
\hline Curative resection & $99.4 \%$ & $98.8 \%$ & $97.1 \%$ \\
\hline Non-curative resection & $99.4 \%$ & $98.9 \%$ & $96.8 \%$ \\
\hline
\end{tabular}

Fig. 4. Kaplan-Meier analysis for cumulative overall survival rates according to non-curative resection. Log-rank $p=0.788$.

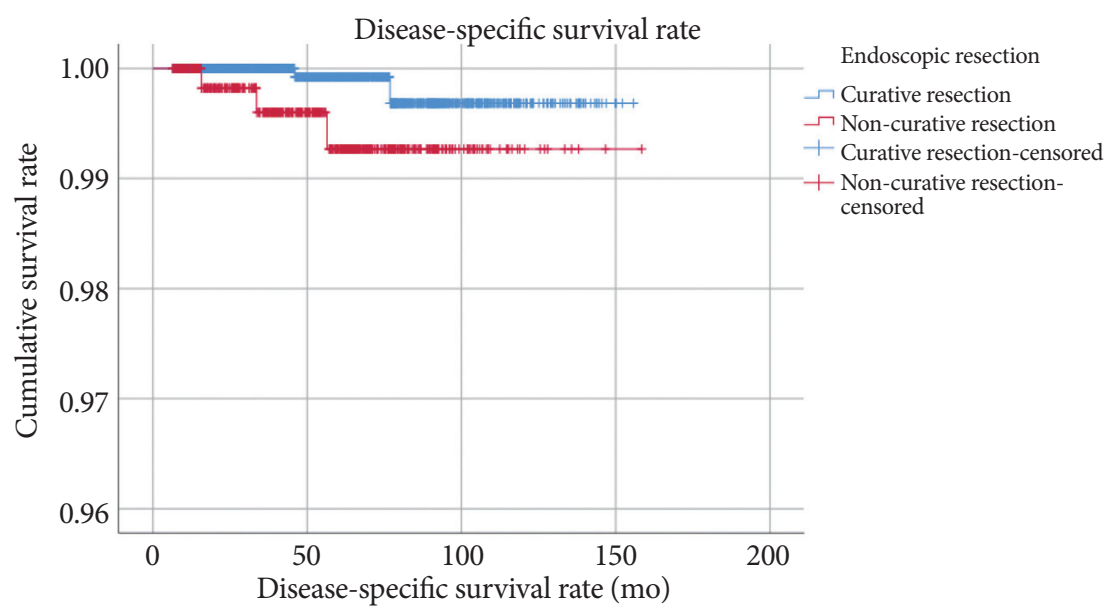

\begin{tabular}{lccc}
\hline Disease-specific survival time & $3 \mathrm{yr}$ & $5 \mathrm{yr}$ & $10 \mathrm{yr}$ \\
\hline Curative resection & $100 \%$ & $99.9 \%$ & $99.7 \%$ \\
\hline Non-curative resection & $99.6 \%$ & $99.3 \%$ & $99.3 \%$ \\
\hline
\end{tabular}

Fig. 5. Kaplan-Meier analysis for cumulative diseasespecific survival rates according to non-curative resection. Log-rank $p=0.038$.

\section{DISCUSSION}

The aim of this retrospective multicenter study was to analyze the risk factors associated with NCR and the long-term clinical outcomes of NCR with no additional treatment in a large-scale population of patients.

According to several studies, the incidence of NCR after endoscopic resection of EGC is approximately $11.9 \%-18.5 \%{ }^{15,19,21-23}$ In our study, the incidence of NCR was $21.4 \%$, which was somewhat higher than that reported in other studies. In Korea, the number of ESD procedures is steadily increasing because of several factors, including an increase in the number of individual health examinations and the expansion of national cancer screening programs. ${ }^{5}$ In addition, ESD is now more frequently performed with larger lesions since the introduction of the expanded criteria for ESD of EGC. ${ }^{13}$

The aim of endoscopic resection of EGC is CR; however, unintended NCR may occur owing to various factors. Several previous studies have analyzed the risk factors associated with NCR in endoscopic resection of EGC. In a study of 784 patients who underwent ESD, the risk of NCR was the highest in patients with a tumor size of $>3 \mathrm{~cm}$, the presence of an ulcer, and a tumor located in the upper body. ${ }^{21}$ In Korea, 1,639 patients with EGC who underwent ESD were retrospectively analyzed for risk factors associated with NCR. The seven factors found to be associated with NCR in that study were large tumor size ( $\geq 2 \mathrm{~cm}$ ), tumor location in the upper body, presence of an ulcer, fusion of gastric folds, absence of mu- 
cosal nodularity, spontaneous bleeding, and undifferentiated tumor. The higher the score, the higher the risk of NCR. ${ }^{24}$ In addition, a study reported that a tumor size of $>2 \mathrm{~cm}$, a superficial elevated and depressed type, and an undifferentiated type were risk factors for NCR. ${ }^{25}$ In addition to the characteristics of the lesion at the time of the procedure, the effects of an operator's endoscopic technique and the pre- and post-procedure discrepancies in NCR were analyzed in one study. ${ }^{22}$ By combining the results of these previous studies, the risk factors associated with NCR in endoscopic resection of EGC were large tumor size, tumor location in the upper body, ulceration, undifferentiated tumor, indications falling outside of the absolute and expanded indications for endoscopic resection, improper endoscopic technique, and discrepancies in diagnosis before and after the treatment. These results were not significantly different in our study.

In our study, we analyzed the local recurrence rate and its associated risk factors after ESD. Local recurrence was observed in $10.6 \%$ of the ESD sites in the NCR group during the median follow-up period of approximately 50 months, and this rate was significantly higher than the local recurrence rate of $2.5 \%$ in the CR group. The risk factors affecting local recurrence in this study were tumor size $\geq 2 \mathrm{~cm}$, submucosal invasion, positive horizontal margin, and lymphovascular invasion. Previous studies that analyzed the risk factors for local recurrence after endoscopic resection showed similar results. A study that analyzed 152 cases of NCR of EGC reported that there was a high risk of local recurrence in cases of incomplete resection, in cases that exceeded the ESD criteria, and in cases with lymphovascular invasion. ${ }^{26}$ A study that analyzed 222 patients with EGC treated with ESD reported that a positive horizontal margin, piecemeal resection, and lymphovascular invasion were risk factors for local recurrence. ${ }^{27}$ In two studies in patients with a positive horizontal margin after NCR of EGC, the risk of local recurrence was the highest in patients with a positive horizontal margin of $>6 \mathrm{~mm}$ length. ${ }^{11,28}$

In our study, there was no difference in the OS rate between the CR and NCR groups when patients received no additional treatment, but the DSS rate was significantly lower in the NCR group than in the CR group. This means that the OS rate is offset by the difference between the two groups due to various causes of death; however, given the specificity of survival in gastric cancer, the incidence of gastric cancer-related death in the NCR group was higher than that in the CR group. In other words, additional treatment should be considered for patients with NCR because the DSS rate may be lower without additional treatment in these patients. There are several studies that support our results. In a retrospective study of EGC cases that were outside the indications for endoscopic resection, 1,799 patients who underwent gastrectomy as the first treatment were compared with 219 patients who underwent endoscopic resection as the first treatment, There was no significant difference in mortality and gastric cancer recurrence rates between patients who initially underwent gastrectomy and patients who underwent gastrectomy after NCR; however, the mortality and gastric cancer recurrence rates were significantly higher in patients who did not undergo gastrectomy after NCR than in those who underwent gastrectomy as the first treatment. ${ }^{29}$

Our study has some limitations. First, as it is a retrospective study, there may be some bias in patient selection. However, we believe that such a bias is compensated for by the largescale multicenter design. Second, this study included data on local recurrence in the post-ESD prognosis, but no data were collected on lymph node metastasis or distant metastasis after ESD. Third, in the survival analysis, the survival rate was analyzed only in patients with CR and in those who received no additional treatment after NCR. We believe that it is also necessary to analyze the survival rate in patients who received additional treatment, such as redo-ESD or gastrectomy after NCR.

In summary, the risk factors for NCR were older age, undifferentiated tumor, upper location of the tumor, tumor size $>2 \mathrm{~cm}$, and presence of an ulcer. The local recurrence rate was significantly higher in NCR, and the risk factors for local recurrence are tumor size $>2 \mathrm{~cm}$, submucosal invasion, horizontal margin positive, and lymphovascular invasion. In terms of survival, the DSS rate was significantly lower in NCR without further treatment than in CR. Therefore, if patients can tolerate surgical treatment, additional surgery is recommended in cases of NCR after ESD for EGC.

\section{Conflicts of Interest}

This study was supported by a grant from the Korean Gastrointestinal Endoscopy Research Foundation.

\section{Acknowledgments}

The authors thank Suck Chei Choi, Jun-Hyung Cho, Kwang Bum Cho, Jae Young Jang, Jae Myung Park, Jae Kyu Sung, Moon Kyung Joo, Jung Won Jeon, Weon Jin Ko, Sun Moon Kim, Yeong Dae Kim, Chan Gyoo Kim, Eun Ran Kim, Gwang Ho Baik, Dong Hoon Baek, Chul-Hyun Lim, and Hyun Joo Jang.

\section{REFERENCES}

1. Karimi P, Islami F, Anandasabapathy S, Freedman ND, Kamangar F. Gastric cancer: descriptive epidemiology, risk factors, screening, and prevention. Cancer Epidemiol Biomarkers Prev 2014;23:700-713.

2. Jung KW, Won YJ, Oh CM, Kong HJ, Lee DH, Lee KH. Cancer statistics in Korea: incidence, mortality, survival, and prevalence in 2014. Cancer Res Treat 2017;49:292-305.

3. Tsukuma H, Oshima A, Narahara H, Morii T. Natural history of ear- 
ly gastric cancer: a non-concurrent, long term, follow up study. Gut 2000;47:618-621.

4. Mun YG, Choi MG, Lim CH, et al. Factors affecting endoscopic curative resection of gastric cancer in the population-based screening era. Clin Endosc 2018;51:478-484.

5. Kang KJ, Lee JH. Characteristics of gastric cancer in Korea - with an emphasis on the increase of the early gastric cancer (EGC). J Korean Med Assoc 2010;53:283-289.

6. Kim YI, Kim YW, Choi IJ, et al. Long-term survival after endoscopic resection versus surgery in early gastric cancers. Endoscopy 2015;47:293301.

7. Pyo JH, Lee $\mathrm{H}, \mathrm{Min} \mathrm{BH}$, et al. Long-term outcome of endoscopic resection vs. surgery for early gastric cancer: a non-inferiority-matched cohort study. Am J Gastroenterol 2016;111:240-249.

8. Kim SG, Ji SM, Lee NR, et al. Quality of life after endoscopic submucosal dissection for early gastric cancer: a prospective multicenter cohort study. Gut Liver 2017;11:87-92.

9. Kim JH. Strategy for curative endoscopic resection of undifferentiated-type early gastric cancer. Clin Endosc 2019;52:9-14.

10. Japanese Gastric Cancer Association. Japanese gastric cancer treatment guidelines 2014 (ver. 4). Gastric Cancer 2017;20:1-19.

11. Sekiguchi M, Suzuki H, Oda I, et al. Risk of recurrent gastric cancer after endoscopic resection with a positive lateral margin. Endoscopy 2014;46:273-278.

12. Sekiguchi M, Suzuki H, Oda I, et al. Favorable long-term outcomes of endoscopic submucosal dissection for locally recurrent early gastric cancer after endoscopic resection. Endoscopy 2013;45:708-713.

13. Nonaka S, Oda I, Nakaya T, et al. Clinical impact of a strategy involving endoscopic submucosal dissection for early gastric cancer: determining the optimal pathway. Gastric Cancer 2011;14:56-62.

14. Bae SY, Jang TH, Min BH, et al. Early additional endoscopic submucosal dissection in patients with positive lateral resection margins after initial endoscopic submucosal dissection for early gastric cancer. Gastrointest Endosc 2012;75:432-436.

15. Kim SG. Treatment strategy after incomplete endoscopic resection of early gastric cancer. Clin Endosc 2016;49:332-335.

16. Lee SH, Park BS. Is radical surgery necessary for all patients diagnosed as having non-curative endoscopic submucosal dissection? Clin Endosc 2019;52:21-29.

17. Ahn JY, Jung HY, Choi JY, et al. Natural course of noncurative en- doscopic resection of differentiated early gastric cancer. Endoscopy 2012;44:1114-1120

18. Kawata N, Kakushima N, Takizawa K, et al. Risk factors for lymph node metastasis and long-term outcomes of patients with early gastric cancer after non-curative endoscopic submucosal dissection. Surg Endosc 2017;31:1607-1616.

19. Hatta W, Gotoda T, Oyama T, et al. Is radical surgery necessary in all patients who do not meet the curative criteria for endoscopic submucosal dissection in early gastric cancer? A multi-center retrospective study in Japan. J Gastroenterol 2017;52:175-184.

20. Japanese Gastric Cancer Association. Japanese classification of gastric carcinoma: 3rd English edition. Gastric Cancer 2011;14:101-112.

21. Hirasawa K, Kokawa A, Oka H, et al. Risk assessment chart for curability of early gastric cancer with endoscopic submucosal dissection. Gastrointest Endosc 2011;74:1268-1275.

22. Toyokawa $\mathrm{T}$, Inaba $\mathrm{T}$, Omote $\mathrm{S}$, et al. Risk factors for non-curative resection of early gastric neoplasms with endoscopic submucosal dissection: analysis of 1,123 lesions. Exp Ther Med 2015;9:1209-1214.

23. Suzuki H, Oda I, Abe S, et al. Clinical outcomes of early gastric cancer patients after noncurative endoscopic submucosal dissection in a large consecutive patient series. Gastric Cancer 2017;20:679-689.

24. Kim EH, Park JC, Song IJ, et al. Prediction model for non-curative resection of endoscopic submucosal dissection in patients with early gastric cancer. Gastrointest Endosc 2017;85:976-983.

25. Ohara Y, Toshikuni N, Matsueda K, Mouri H, Yamamoto H. The superficial elevated and depressed lesion type is an independent factor associated with non-curative endoscopic submucosal dissection for early gastric cancer. Surg Endosc 2016;30:4880-4888.

26. Han JP, Hong SJ, Kim HK, et al. Risk stratification and management of non-curative resection after endoscopic submucosal dissection for early gastric cancer. Surg Endosc 2016;30:184-189.

27. Kim JH, Lee JH, Chung JW, et al. Risk factors for local recurrence of early gastric cancer after endoscopic submucosal dissection. Korean J Med 2013;85:285-293.

28. Kim TK, Kim GH, Park DY, et al. Risk factors for local recurrence in patients with positive lateral resection margins after endoscopic submucosal dissection for early gastric cancer. Surg Endosc 2015;29:2891-2898.

29. Eom BW, Kim YI, Kim KH, et al. Survival benefit of additional surgery after noncurative endoscopic resection in patients with early gastric cancer. Gastrointest Endosc 2017;85:155-163.e3. 